\title{
Discussion on Diversified Oil Painting Teaching
}

\author{
Yanni Wu \\ The Department of Oil Painting, Xi'an Academy of Fine Arts , 710065
}

\author{
Keywords: Diversity; Oil Painting; Teaching; Curriculum; Innovation
}

\begin{abstract}
Colleges and universities are the forefront place of specialized personnel training in our country. In the new era of economic and social development in our country, the state's requirements for the comprehensive literacy of specialized personnel continue to increase. However, there are still many defects in Chinese personnel training mode in colleges and universities due to the historical and institutional reasons. The traditional teaching mode of education has seriously hindered the quality of talent of Chinese colleges and universities under the background of quality education. Therefore, as an important part of higher education, the reform of college oil painting is imperative. This paper gives a brief exposition of the current situation of oil painting teaching in colleges and universities, analyzes the characteristics of diversified oil painting teaching and the role of teaching promotion and discusses the reform measures.
\end{abstract}

\section{Introduction}

Strictly speaking, oil painting art is a kind of imported goods. The art of oil painting comes into our country from the west and takes root in the development. It eventually becomes an art form accepted and loved by the public for nearly a hundred years. As a representative of the western painting system, oil painting has brought a great influence on the development of Chinese art and painting with its gorgeous colors, profound and varied expressions and powerful visual impact.

After the founding of New China, we have set up several fine art institutes one after another and gradually forms an oil painting teaching system centered on realism. After all these years of construction and development, many colleges and universities in our country have set up oil painting major and college oil painting education has become the main place for the output of relevant art talents. With the development of the times and the progress of society, especially since the reform and opening up, more and more art forms and works have been reflected in the eyes of the public. The aesthetic vision of the public has been greatly expanded, and the cultural industry in our country has also spread rapidly. However, the corresponding college oil painting teaching develops slowly. There are two reasons for that as following. On the one hand, most of the investment made by colleges and universities in our country is undertaken by the government. Therefore, in the case of limited state financial resources, a large amount of money is invested in the major projects urgently needed by the state. Whether teachers or hardware and software inputs on art specialty is significantly inadequate. On the other hand, the oil painting majors in colleges and universities in our country tend to be conservative both in the mode of running schools and in the setting of curriculums due to the shackles of the traditional concepts and institutions.

\section{Current Situation of College Oil Painting Teaching}

In recent years, with the continuous improvement of people's living standards, the public's demand for spiritual and cultural consumption has shown explosive growth. Under the strong support of the state, the art specialty has a rapid development. However, no matter whether the policy help or the capital invested, the solution is always the external cause. It is still a long way to go to completely change the many problems existing in the teaching of oil painting in colleges and universities in our country. Many Chinese scholars have made double exploration in theory and practice on how to solve the problems existing in college oil painting teaching in our country, and have also made some achievements and experiences. The author has engaged in front-line teaching for many years and he believes that the problems in Chinese oil painting teaching can be attributed to the following 
points.

Single Teaching Method. It goes without saying that the problem of single teaching method has plagued almost all disciplines. In recent years, with the advancement of scientific and technological means and information construction, many disciplines have achieved fruitful results in solving the problem of simplifying teaching methods. Unfortunately, this does not include oil painting. Oil painting teaching is a educational process with rich connotation that needs to comprehensive use of oil painting expertise, pedagogy and psychology and other disciplines, which are hard to be strengthened and resolved through technical means. Currently, there is still a big gap between the teaching staffing of oil painting major in colleges and the requirements for the development and construction of oil painting profession. Many oil painting teachers in colleges and universities enter in the Academy of Fine Arts through art exams, so they have a single knowledge system and even many people do not have the expertise in other related fields. Teachers of normal colleges and universities have relatively perfect knowledge system and some teaching experience and skills, but liberal arts graduates have weak ability to control information technology. Many teachers also have some very good supporting educational teaching ideas, but they are very difficult to achieve. Many of them eventually are failed and return to traditional educational means.

Curriculum Setting Is Unreasonable. The science of curriculum is directly related to the training objectives can be successfully implemented and realized. At present, there are still many places in our country's colleges specializing in oil painting that do not meet the teaching requirements and the students' ability to improve. For example, the initial color course is mainly gouache and many students in the later creation has been using the thick coating technology. From recognizing to creation, there is not a completely clear and profound understanding of oil painting. When such a deviation occurs, the lecturer does not take corrective action to compensate, allowing students to enter the detours from the beginning. The relationship between sketching and creation was originally closely related. It is best to join the creative concept in the specific sketch training so that the dull classwork can become entertaining. However, many colleges and universities will separate them in the curriculum setting and there is no cohesive curriculum, which is easy for students to have a rigid sense of out of touch.

Unilateral Emphasis on Professional Knowledge. Oil painting needs some professional skills, but this does not mean that the painting skills are the whole content of oil painting creation. Oil painting as a subject in humanities and arts, creators without the necessary humanities is difficult to master what they have learned. Creators who lack cultural accomplishments of oil painting can only be called a craftsman, but can not become a master. As a kind of artistic expression, oil painting is a complex of creators' thoughts, creator's own cultural heritage and perception of life, emotional world and spiritual world. At present, oil painting education in colleges and universities unilaterally emphasizes the education of professional skills and knowledge and despise theory and the cultivation of humanistic quality. The cultural foundation of college students majoring in oil painting is relatively weak. Under this educational mode, the works created by students are hardly able to make breakthroughs in the cultural connotation and spiritual realm. It is an intrinsic demand for the healthy development of oil painting profession to carry out humane education in college oil painting teaching as well as an extension of quality education and is a specific way to comprehensively improve students' ability and accomplishment. Besides, humanities education can enrich students' thinking, broaden students' artistic horizons and to a certain extent strengthen students' sense of innovation. Through humanistic education, students can have a deeper understanding of real life and society, improve their artistic perception and lay a solid theoretical foundation for their follow-up professional development. However, our current teaching of oil painting in colleges neglects the role of human factors. This educational mode seriously hinders the cultivation of students' artistic ability and the development of artistic qualities.

Blind Emphasis on Innovation. We advocate innovation and think that innovation is the driving force for the development of the times and professional progress. However, we should not blindly believe in innovation and ignore the external and internal conditions needed for innovation. We have some misunderstandings about the cultivation of students' innovative ability and innovative 
thinking in the education of college painting. For example, it will led to some students think that oil painting is an abstract idea if teachers encourage them to innovate blindly when students' overall abilities are not good enough in their conceptions and skills, and even they will indulge in pursuing many novel and weird behaviors. In order to get rid of the unity of teaching, some teachers directly lay aside the traditional training methods, engage in innovation and take a new road, ignoring the basic forms of oil painting creation and neglecting the basic functions of basic skills in student development, which constrains the development of students.

\section{Diversified Teaching Mode Strategy}

From the practice of oil painting teaching in colleges and universities, taking the diversified teaching mode is the only way to conform to the requirements of the times and to the individual development of college students majoring in oil painting. Promote diversified teaching of oil painting should focus on the following aspects.

Reform the Teaching System. In the teaching system, we should change the drawbacks that current neglect the cultivation of the comprehensive ability of students. In the reform of the teaching system, we can learn from the successful experiences of the West in this field and formulate humanistic, scientific and feasible personnel training programs and curriculum system based on the analysis of the characteristics of our country's higher education and the development of schools. The studio system is an important achievement in teaching reform. This system breaks the limitation between upper and lower grades of students, allowing students and teachers, students and students to communicate with each other about creation and feeling and learn from each other. At the same time, this teaching method enhances the emotion between teachers and students. In the reform of teaching contents, we should strive to break the current situation that oil painting courses is in absolute dominant position, and introduce appropriate amount of cultural courses to solve the problems of single teaching content and low level of students' cultural quality development. In the teaching philosophy, oil painting profession can not always stick to and focus on the traditional concepts of the profession to start education and creation, but to constantly update the concept of art and to keep up with the new trend of international art development. It is necessary to pay attention to coordinating the goal of personnel training with the needs of social development and to guide the teaching work with advanced educational concepts. Take the essence of the advanced teaching thoughts of other foreign schools and combine with the actual teaching practice to develop and innovate the teaching system in practice.

Pay Attention to the Cultivation of Students' Humanities Accomplishment. In education and teaching, teachers should pay attention to the cultivation of students' comprehensive ability and humanistic accomplishment, which can be drawn from the analysis of the western painting education mode. Western painting education attaches great importance to the cultivation of humanistic accomplishments. Their view of art is seldom utilitarian and purposeful. They regard art education as the intrinsic motivation to promote the long-term development of students and create a relatively free and relaxed environment for students in teaching. We can no longer regard the teaching of oil painting as a simple teaching of skills and learning. Instead, it should be considered on the strategic level of personnel training that teachers improve humanistic quality and comprehensive ability and shape aesthetic ability and taste of students. Besides, reasonably add interdisciplinary electives to the curriculum so that students have more platforms and opportunities to learn and understand other relevant professional knowledge, which can expand students' knowledge and enrich students' knowledge system. Actively guide the construction of campus culture and create invisible classrooms for the growth and development of students, so that they are nurtured by the spirit and knowledge in a subtle way. In cultivating students' specific links, teachers should also be good at discovering differences in personality and interests among different students, teaching in accordance with their aptitudes and cultivating the true feelings of students on the creation of oil paintings.

Treat Innovation Correctly. It is good to adhere to the original intention of innovation in oil painting teaching and the most important is how to innovate. Innovation is a mirage for students 
who either have no specific idea of innovation or do not know how to innovate. Innovation must be based on a certain foundation as a starting point rather than on the infinitude of sloppy acts. The correct method for innovation should be that teachers lead students to observe and sentiment life and then to create after students have a certain foundation of creation. When students have innovative ideas, teachers should respect them and patiently listen to students innovative ideas rather than deny them and blow the enthusiasm and initiative of student.

Establish A Scientific and Detailed Teaching Evaluation System. The establishment and perfection of teaching evaluation system is a very important part of diversified teaching reform of oil painting in colleges and universities, which has practical significance for the continuous promotion and steady improvement of the reform. The evaluation system should be based on the principles of comprehensiveness, objectivity, science, operability and timely feedback. It not only pays attention to the examination of the teaching quality of teachers, but also includes the reasonable suggestions of students on the curriculum, teaching suggestions and so on. It is necessary to combine the vertical evaluation with the parallel evaluation so as to promote the reform and construction. In a sense, the system of scientific evaluation system is the key to the success of curriculum reform.

Strive to Improve Teachers' Comprehensive Literacy. Curriculum reform is always accompanied by the improvement of teachers' ability and literacy. Teachers' accomplishment involves many aspects, of which the most important is the improvement of the concept of education and teaching. Teachers should pay attention to cutting-edge teaching philosophy and teaching methods and gradually create a creative form for their own teaching combined with their own teaching practice. Second, the diversified teaching mode not only requires teachers to have the skill of oil painting creation, but also has a profound knowledge of discipline synthesis theory. However, this ability can not be formed overnight. Therefore, the majority of teachers should pay attention to their daily accumulation and improve their ability with a high degree of self-awareness and sense of mission.

\section{Conclusion}

Teaching reform of oil painting major in colleges and universities is the only way to improve the quality of oil painting professionals at present. As relevant professional educators, we should follow the pace of the reform of curriculum education, change the traditional way of thinking, reform teaching mode and promote the teaching reform of oil painting to the depth with the sense of urgency and mission.

\section{Reference}

[1] H. Shang. Ethnic School of Exploration of Oil Painting in the Real World [J]. China Oil Painting Market, 2011, (5).

[2] S. Y. Zhang. Discussion on the Development and Reform of Oil Painting Teaching in Colleges and Universities [J]. The Theater House, 2016 (3): 158-159.

[3] X. Yang. Talking about the Development and Transformation of Oil Painting Teaching in Colleges and Universities [J]. Art and Technology, 2015 (8): 166-167.

[4] K. J. Li. Talking about the Development of Chinese College Oil Painting Teaching and Reform Measures [J]. Art Education Research, 2013 (37): 63-65.

[5] L. Ke. Discussion on Diversification of Modern Oil Painting Teaching in Chinese Universities [J]. Art Review, 2015 (12): 56-57.

[6] X. Y. Meng. The Value of Diversified Teaching in Oil Painting Teaching in Chinese Universities [J]. Electronic Manufacturing, 2014 (19): 12-13.

[7] Y. Huang. Reflections on the College Oil Painting Teaching from the Perspective of Diversified Development of Oil Painting [J]. Popular Arts, 2015 (13): 78-79.

[8] Q. Tang. Analysis of Innovative Reform of Diversified Teaching in Oil Painting Teaching in Chinese Universities [J]. America and the Ara (middle) · Art Journal, 2016 (5): 31-32. 
[9] J. D. Dai. Discussion on Diversification of Contemporary Chinese Oil Painting Teaching [J]. Young Literature, 2013 (3): 61-62.

[10]D. P. Zhang. My Opinion on Teaching Reform of College Oil Painting [J]. Series of Drama, 2012.

[11]W. Shan. Discussion on the Teaching Reform of College Oil Painting [J]. Chinese Journal, 2013.

[12]J. J. Liu. Reconstruction and Innovation of Basic Art Teaching System of Color Art in Colleges and Universities [D]. Hunan Normal University, 2007.

[13]H. J. Wang. Introduction to Art. Culture and Arts Press, 2000. 